Proceedings of XIX International Scientific Conference "New Technologies and Achievements in Metallurgy, Material Engineering, Production Engineering and Physics", Częstochowa, Poland, June 7-8, 2018

\title{
A Study of Metal-Ceramic Composite Foams Combustibility
}

\author{
K. Gawdzińska ${ }^{a}$, L. Chybowski ${ }^{b, *}$, M. NABialek ${ }^{c}$ And P. Szymański ${ }^{d}$ \\ ${ }^{a}$ Maritime University of Szczecin, Faculty of Marine Engineering, Division of Naval Materials Engineering, \\ Willowa 2-4, 71-650 Szczecin, Poland \\ ${ }^{b}$ Maritime University of Szczecin, Faculty of Marine Engineering, Marine Propulsion Plants Department, \\ Wały Chrobrego 1-2, 70-500 Szczecin, Poland \\ ${ }^{c}$ Institute of Physics, Faculty of Production Engineering and Materials Technology, \\ Częstochowa University of Technology, al. Armii Krajowej 19, 42-200 Częstochowa, Poland \\ ${ }^{d}$ Poznań University of Technology, Faculty of Mechanical Engineering and Management, \\ Institute of Materials Technology, Piotrowo 3, 60-965 Poznań, Poland

\begin{abstract}
This paper presents a study of the non-combustibility of cast metal-ceramic composite foams, specified in PNEN ISO 1182:2010 (Reaction to fire tests for products - Non-combustibility test). It was explained why foams with AlSi11 warp and $\mathrm{SiC}$ reinforcement are non-flammable. The paper describes relationship between the compressive stress values and compression strain values for three foams - aluminium foam, AlSi11/SiC composite foam, not subjected to flammability test, and AlSi11/SiC composite foam, subjected to flammability test. No difference between strength of combustible and incombustible foams was found. This study aims to determine the firefighting features of the materials described herein, which can be used, among many, in naval industry.
\end{abstract}

DOI: 10.12693/APhysPolA.135.304

PACS/topics: casting, composites, metal-ceramic foams, material combustibility

\section{Introduction}

Materials are conventionally divided into combustible and non-combustible categories. Non-combustible materials are materials that, according to international definition, when heated up to $750^{\circ} \mathrm{C}$ do not burn and do not emit flammable gases at sufficient levels to burn, nor do they emit heat at sufficient levels to cause an increase in furnace temperature [1]. Materials that do not fulfil this condition are classified as combustible. Despite the common, international definition of noncombustible materials, there are many methods of study and evaluation criteria for material non-combustibility. Among the most widespread and characteristic is a method of non-combustibility testing based on ISO 1182. Authors tried to develop new materials (metal foams) that could fulfil criteria of this standard and simultaneously have assumed strength properties and specific gravity.

Fire resistance in composite metal foams means that they maintain their cellular structure at high temperatures and do not emit smoke or toxic chemical compounds (organic insulating foams traditionally used in ships emit phosgene and other gases. Metal foams keep their insulating properties even if the humidity of the environment is high). Such properties have been found in composite metal-ceramic foams based on aluminium alloy (Al-alloy) and carbide or oxide ceramics with specific gravities rang-

*corresponding author; e-mail: 1.chybowski@am.szczecin.pl ing from $0.25-0.40 \mathrm{~g} / \mathrm{cm}^{3}$. Figure 1 shows samples of the above-mentioned foams after annealing at a temperature of $1000^{\circ} \mathrm{C}$.
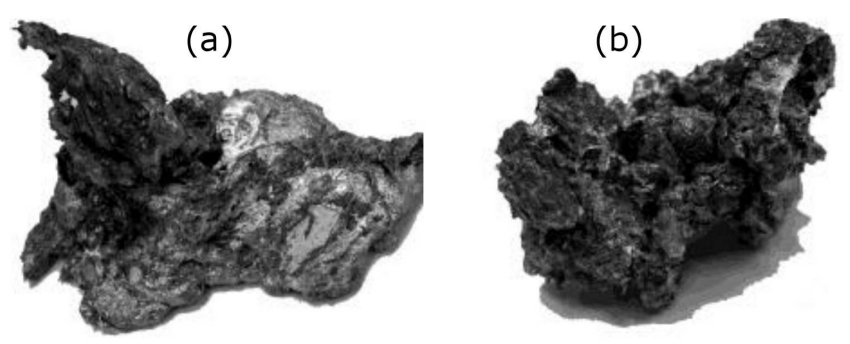

Fig. 1. Samples of aluminium foam (a) and foam made of AlSi7Mg composite $+15 \% \mathrm{SiC}$ (b) after annealing at a temperature of $1000^{\circ} \mathrm{C}$.

Initial tests of melting aluminium-based foams and composites with an Al-alloy matrix have shown that heating foam samples to a temperature higher than the liquid temperature of the alloy or composite (even to $1000^{\circ} \mathrm{C}$ ) does not result in a homogeneous liquid metal [2]. Observations were as follows:

- for a foam made of aluminium using titanium hydride the result was a semi-fluid suspension, in some places changing into a solid phase with a powdery texture (Fig. 1a);

- for a foam obtained by blowing gas into a liquid composite comprising an Al-alloy matrix reinforced with $\mathrm{SiC}$ grains (15\% metal mass) the result was that the foam did not change its form (Fig. 1b). 
The aim of this work was to determine the fire-fighting properties of metal composite foams, thereby testing their possible applications, for example in naval transport as lightweight, fireproof installations [3].

\section{Methodology}

The study materials were metal-ceramic (AlSi11/SiC) foams, manufactured by the gas injection method that utilises direct injection of gas into the liquid composite. The molten composite is introduced into the tank of the foaming device with the temperature stabilised at $720^{\circ} \mathrm{C}$. Once the temperature is fixed, the agitator is run continuously, the inclined tank is set horizontally while the rotor, spinning at $150 \mathrm{rpm}$, is immersed in the tank. The gas output was set at $8 \mathrm{dm}^{3} / \mathrm{min}$. Air was used to foam the composite. This is a difficult method in terms of processing, but it gives great freedom in the selection of foam materials and foaming gases allowing for a wide range of structures and properties to be achieved [3-5].

Porosity obtained using this method stays within the range of $78 \%$ to $92 \%$, while pore size varies between 1 and $8 \mathrm{~mm}$. The samples were prepared according to the requirements of the standard [4,5], using a hydraulic press, then they were weighed and placed in the furnace. Samples were placed in the laboratory furnace to study material non-combustibility.

The method of non-combustibility testing was developed for materials emitting low amounts of heat and burning with a flame only when they are heated up to a temperature close to $750^{\circ} \mathrm{C}$ by $30 \mathrm{~min}$. A study of the non-combustibility of materials according to ISO 1182 is conducted using an electric tube furnace of internal diameter equal to $75 \mathrm{~mm}$.

\section{Compressive strength testing of the foams}

The foams were subjected to a static strength test by axial compression to verify how the temperature influences the tension in the foamed composite. The tests were carried out using the H10K-T strength testing machine and prismatic foam samples with dimensions of $40 \mathrm{~mm} \times 40 \mathrm{~mm} \times 20 \mathrm{~mm}$. The results are presented in Fig. 2. Three foams were compared, one of which was aluminium foam, not tested for combustibility, containing no reinforcing particles, marked FA. The second was composite foam, not tested for combustibility, marked FC, and the third was a composite foam, marked FCT, previously tested for combustibility according to ISO 1182.

When analysing the data presented in Fig. 2, it should be taken into account that the tested foams differed in their density; however, their porosity values were similar. The FA foam had a density of $0.242 \mathrm{~g} / \mathrm{cm}^{3}$ (porosity $91.02 \%$ ), the composite foams' densities were: FC $0.458 \mathrm{~g} / \mathrm{cm}^{3}$ (porosity 90.03\%) and FCT $0.440 \mathrm{~g} / \mathrm{cm}^{3}$ (porosity $89.6 \%$ ).

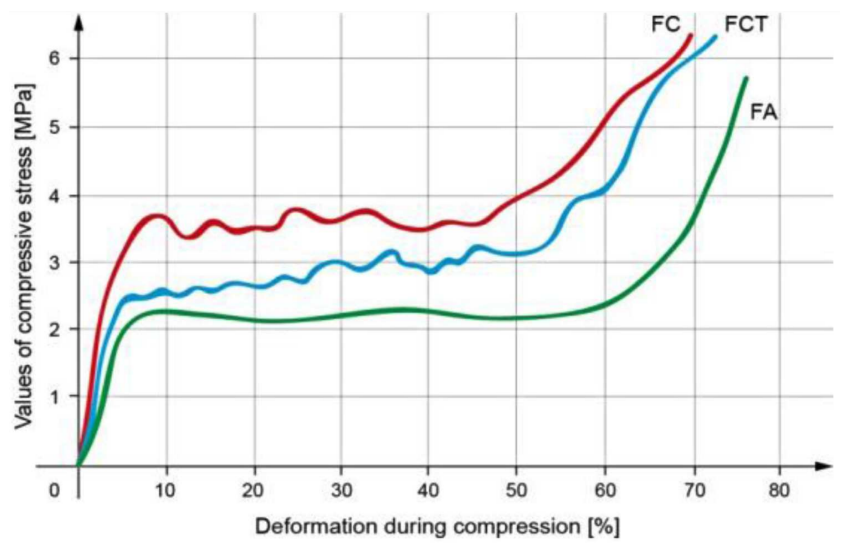

Fig. 2. The relationship between the compressive stress values and compression strain values for three foams: $\mathrm{FA}$ - aluminium foam, $\mathrm{FC}$ - AlSi11/SiC composite foam, and $\mathrm{FCT}$ - AlSi11/SiC composite foam, flammable.

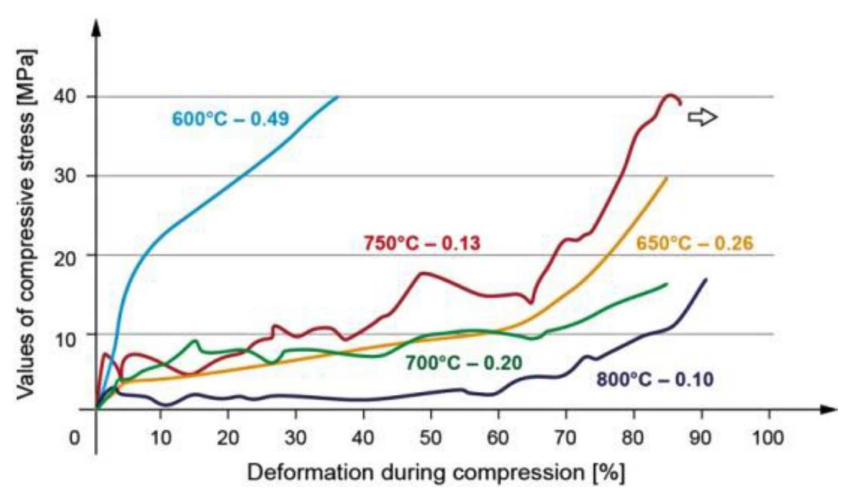

Fig. 3. Stress-strain curves for aluminium foams with different relative densities $[5,6]$.

By analysing the stress-strain relationship a qualitative comparison can be made. Each of the plotted curves forms a similar wave and can be divided into three phases related to the progress of destruction of the foams' microstructures during the tests. The first stage, where there is a strain of only a few percent, corresponds to a linear stress-strain relationship. This is followed by a section in which the average stress remains constant or increases slightly, close to several dozen percent. In the final stage, when the degree of deformation becomes significant (above 50-60\%), the stress increases substantially with minor changes in strain. Confirmation of this phenomenon has been described previously in the literature $[2,6]$ (for aluminium foams with a relative density from 0.1 to $0.26 \mathrm{~g} / \mathrm{cm}^{3}$ ) the plateau occurs up to approximately $60 \%$ (Fig. 3).

The stress values shown in Fig. 3 clearly show that the lower the total porosity, the higher the stress required for deformation to occur. Another difference is: the waveform of the curve in the second stage of deformation for the aluminium foam is relatively "smooth", while for the 
foams made of composite materials, the stress values fluctuate considerably. This is most probably due to the inhibitory effects of the ceramic additives that prevent plastic strain in metal, causing a local accumulation of stresses. The amplitude of the observed fluctuations is related to the density of the foam; the higher the density, the greater the fluctuations of stress during deformation. The composite foams have a higher strength than aluminium FA foams (Fig. 2).

This is related to the presence of reinforcement material. Among the composite foams, FC foam exhibits the highest compressive strength and it has both the highest porosity and density; however, the FCT foam exhibits a slightly lower strength in relation to FC foam. This indicates that elevated temperatures do not affect significantly the compressive strength of composite foams. Future articles will elaborate on some important properties of these materials, although they will require thorough investigation.

\section{Discussion}

The waveforms of the strain of the foams in the compression test show differences between the aluminium alloy foams and composite foams, the latter having more favourable properties, which is related to the different geometric structures. In composite foams, the presence of silicon carbide particles causes fluctuations in the stress-strain curve due to the local accumulation of stresses.

Taking into account the important properties of metal foams that are favourable in maritime conditions, it is advisable to modify the structure of a metal foam and to eliminate its transition to the liquid state after exceeding the melting temperature of aluminium. Preventing the metal foam from flowing in fire conditions $\left(750^{\circ} \mathrm{C}\right.$ according to procedure required by IMO) is based on two phenomena. The introduction of particulate matter into the liquid metal at the manufacturing stage may cause breaks in the liquid phase continuity. The second phenomenon is an increase in the number of products of the reaction between the matrix metal and oxygen, which occurs first at the surface of the gas bubble (foam) and proceeds into the depth of metal, according to the law of gaseous diffusion.

The method is appropriate for castings made of metalceramic composites (e.g. AlSi11/SiC) where a given product in the form of a foam is identifiable as a whole as shown in Table I, since no ignition of the studied material was observed.

Due to aluminium's high affinity for oxygen, in accordance with the Pilling and Bedworth principle, $\mathrm{Al}_{2} \mathrm{O}_{3}$ forms an air-tight layer on the bubble surface. The ratio between the molar density of this oxide and the molar density of aluminium is greater than 1 (1.21), which hinders further build-up of the layer. The rate of build-up is determined by the rate of oxygen diffusion through the layer of $\mathrm{Al}_{2} \mathrm{O}_{3}$ to the oxide-metal boundary. This reaction is described by the general rate equation

$$
\frac{\Delta x}{\Delta T}=k_{L} C_{\mathrm{O}_{2}}
$$

where $\mathrm{kL}$ - process rate constant, $\Delta x / \Delta T$ - layer build-up rate, $C_{02}$ - oxygen concentration.

Taking into account the oxygen diffusion rate within the oxide layer, a parabolic rate equation, based on Fick's law, can be obtained

$$
\frac{\Delta x}{\Delta T}=D \frac{C_{\mathrm{O}_{2}}}{x}
$$

where $D-$ coefficient of oxygen diffusion through the oxide layer, $C_{\mathrm{O} 2} / x$ - oxygen concentration gradient in the oxide layer.

Considering the behaviour of this foam at temperatures exceeding the temperature of the metal's melting point, it would be advisable to increase the fraction of $\mathrm{Al}_{2} \mathrm{O}_{3}$ in the volume of the bubbles' walls (part of the metal binds with the oxygen).

TABLE I

Final results of the study (AlSi11/SiC foam).

\begin{tabular}{l|c|c|c}
\hline \hline \multicolumn{1}{c|}{ Name of measured quantity } & Units & $\begin{array}{c}\text { Average } \\
-5 \text { tests }\end{array}$ & $\begin{array}{c}\text { Std. } \\
\text { dev. }\end{array}$ \\
\hline maximal furnace temperature & ${ }^{\circ} \mathrm{C}$ & 778 & 2 \\
maximal specimen surface temperature & ${ }^{\circ} \mathrm{C}$ & 779 & 5 \\
maximal specimen interior temperature & ${ }^{\circ} \mathrm{C}$ & 758 & 4 \\
duration of specimen burning with flame & $\mathrm{S}$ & 0 & 0 \\
furnace temperature increase & ${ }^{\circ} \mathrm{C}$ & 4.2 & 1 \\
specimen surface temperature increase & ${ }^{\circ} \mathrm{C}$ & 3 & 1 \\
specimen interior temperature increase & ${ }^{\circ} \mathrm{C}$ & 3 & 1 \\
relative mass decrease & ${ }^{\circ}$ & 0 & 0
\end{tabular}

\section{Final conclusions}

This study is based on the analysis of thermodynamic phenomena occurring during the heating of a specimen to a high temperature in a furnace. This methodology described herein is intended to determine the noncombustibility of building and ship materials.

According to the accepted definition [1] aluminiumceramic foams are non-combustible as they resist burning at a temperature of $750{ }^{\circ} \mathrm{C}$ for a period of time defined by the standard. Therefore, these foams can be used (after other additional specific studies are conducted) as insulation materials in civil and naval engineering.

In summary, this study shows that metal composite foams are fire-resistant and can be used as refractory materials in the construction of floating marine structures.

\section{Acknowledgments}

The research was carried out under the Grant $1 / \mathrm{S} / \mathrm{IESO} / 17$ in the Maritime University of Szczecin. 


\section{References}

[1] B. Kwiecińska, Sci. J. Maritime Univ. Szczecin 44 187 (2015).

[2] K. Gawdzińska, L. Chybowski, A. Bejger, S. Krile, Metalurgija 55, 659 (2016).

[3] J. Sobczak, Metal Matrix Composites, Institute of Foundry and Institute of Motor Transport, Kraków 2001 (in Polish).
[4] C. Körner, R.F. Singer, Adv. Eng. Mater. 2, 159 (2000).

[5] K. Gawdzińska, M. Gucma, Archiv. Metall. Mater. 60, 305 (2015).

[6] W. Barnat, T. Niezgoda, J. KONES Powertrain and Transport 14, 27 (2007) (in Polish). 